\title{
Synthesis of Porphyrin-Viologen-Anthracene Triad for Construction of Photoactive Pseudorotaxane with Bis( $p$-phenylene)crownether
}

\author{
Eun Ju Shin*
}

Department of Chemistry, Sunchon National University, Suncheon, Jeonnam 540-742, Korea

\begin{abstract}
It is interesting to introduce viologen moiety into photoactive compounds such as porphyrin and anthracene in the study of supramolecular system such as pseudorotaxanes. For the construction of photoactive pseudorotaxane based on porphyrinviologen-anthracene triad or its zinc derivative threaded with bis $p$-phenylene-34-crown-10 macrocycle, porphyrin -viologen-anthracene triad $\mathbf{1}$ and its zinc derivative zinc porphyrin-viologen-anthracene triad $\mathbf{2}$ were prepared and their absorption and fluorescence spectral properties were measured.
\end{abstract}

As top-down approach for the development of miniaturized computer is reaching their limit, much attention has been paid to molecular machines constructed by the bottom-up approach starting from atoms and molecules, for recent years. ${ }^{1}$ Some interlocked molecules, such as pseudorotaxanes, rotaxanes and catenanes may be considered as particular types of molecular level machines or switches. $^{2-9}$ Molecular machine contains a motor consisting of a mobile and a stationary part. The mechanical movements of their molecular component are induced by the displacement of the movable component from the stationary one in response to some external stimulus such as $\mathrm{pH}$, chemical, electrical energy, or light, and result in on/off switching of some observable properties expressed in absorption or luminescence spectra, opening up the way to process information at the molecular level.

Recently, the making of relatively simple pseudorotaxanes, rotaxanes, and catenanes is one of the challenging subjects. Pseudorotaxanes ${ }^{10}$ consist of a macrocyclic ring component and a threadlike linear component. Rotaxanes ${ }^{11}$ consist of a ring component and a dumbbell-shaped component which incorporates

*To whom correspondence should be addressed.

E-mail: ejs@sunchon.ac.kr one or more recognition sites in its rod section and is terminated by bulky "stoppers"s encircled by a ring component. Catenanes ${ }^{12}$ consist of two interlocked macrocyclic ring components.

Many positively charged pseudorotaxanes, rotaxanes, and catenanes were prepared by self assembly of $\pi^{-}$ stacked interaction between viologen and aromatic compound. $^{13}$ It is interesting to introduce viologen moiety into photo-active compounds such as porphyrin and anthracene in the study of supramolecular system such as rotaxanes and catenanes.

Among external stimuli activating the molecular machine, light has many advantages such as no generation of waste products, rapid on/off switching, and easy monitoring. ${ }^{14}$

For studying light-active pseudorotaxane based on the thread component consisting of porphyrin, viologen, and anthracene threaded with macrocyclic ring component such as bis ${ }^{-}$-phenylene-34-crown-10 (BP34Cr10), porphyrin-viologen-anthracene Triad $\mathbf{1}$ and zinc porphyrin-viologen-anthracene Triad $\mathbf{2}$ were prepared and their absorption and fluorescence spectral properties are investigated.

Porphyrins are strong visible light absorbing molecules and frequently employed as electron donor in multicomponent electron transfer systems. ${ }^{15-17}$ Anthracene is a strong UV light absorbing molecule and is used as a typical $\pi$-electron donor. Viologen is a typical electron acceptor. ${ }^{18}$ Combined three components of zinc porphyrin, viologen, and anthracene, it is expected that UV irradiation leads to the generation of excited porphyrin and then photoinduced electron transfer from excited porphyrin to viologen, while visible irradiation results in the formation of the anthracene excited states and consequent photoinduced electron transfer from excited anthracene to viologen. It is expected that photoinduced electron transfer in Triad 1(or Triad 2)/BP34Cr10 pseudorotaxanes induce the dethreading by weakening the electrostatic interaction between viologen moiety and BP34Cr10 (Scheme 1). 


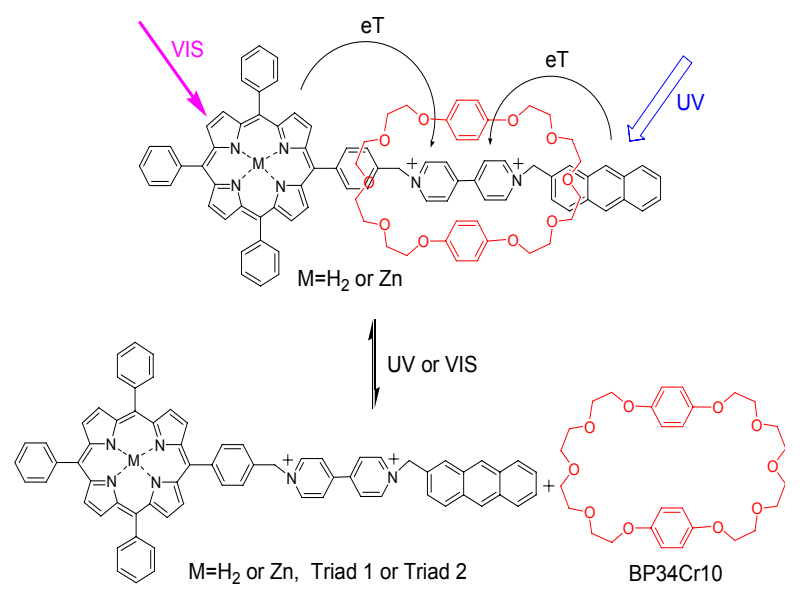

Scheme 1. Dethreading of pseudocatenane composed of Triad 1 or Triad 2 and BP34Cr10 by photoinduced electron transfer using UV or visible light.

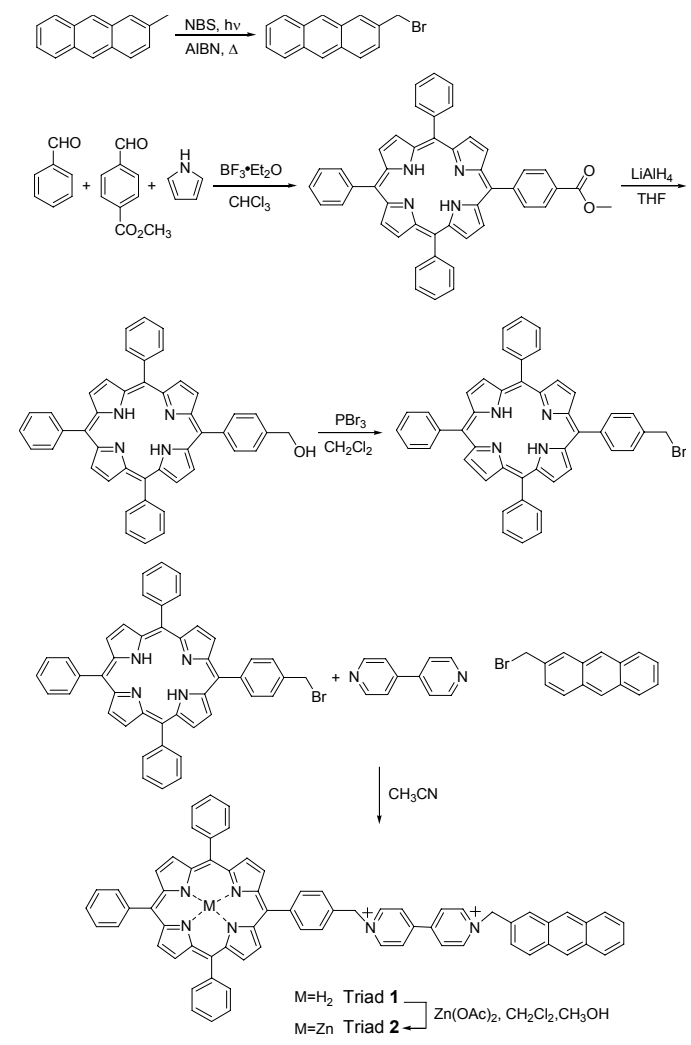

Scheme 2. Synthesis of Triad $\mathbf{1}$ and Triad 2.

Scheme 2 describes synthetic procedure of porphyrin -viologen-anthracene Triad $\mathbf{1}$ and its zinc derivative Triad 2.

2-Bromomethylanthracene was prepared by bromination $^{19}$ of 2-methylanthracene using $\mathrm{N}^{-}$ bromosuccinimide. 5-(Methyl-4-benzoate)-10, 15, 20triphenyl-porphyrin was prepared by stirring the mixture of benzaldehyde( 3 equiv.), methyl 4-formyl benzoate( 1 equiv.), and pyrrole(4 equiv.) in chloroform with $\mathrm{BF}_{3} \cdot \mathrm{Et}_{2} \mathrm{O}(1.2$ equiv. $)$, according to the reported method $^{20,21}$ and was reduced to 5-(4hydroxymethylphenyl)-10,15,20-triphenylporphyrin with the addition of $\mathrm{LiAlH}_{4}$ in freshly distilled tetrahydrofuran and then transformed into 5-(4bromomethylphenyl)-10,15,20-triphenyl-porphyrin with $\mathrm{PBr}_{3}$ in dichloromethane. ${ }^{21}$ Triad 1 (or Triad 2) was prepared by refluxing a mixture of 5-(4bromomethylphenyl)-10,15,20-triphenyl-porphyrin(or its zinc derivative), 2-bromomethylanthracene, and 4,4'bipyridyl in acetonitrile. Triad $\mathbf{2}$ was obtained by the addition of excess zinc acetate into Triad $\mathbf{1}$ in the mixed solvent $(9 / 1, \quad \mathrm{v} / \mathrm{v})$ of dichloromethane and methanol. ${ }^{21}$ Bis- $p$-phenylene-34-crown-10 BP34Cr10 was prepared as in the literature. ${ }^{22-24}$

Figure 1 shows absorption and fluorescence spectra (excitation wavelength $420 \mathrm{~nm}$ ) of Triad $\mathbf{1}$ and an equimolar mixture $\left(1 \times 10^{-5} \mathrm{M}\right)$ of Triad $\mathbf{1}$ and $\mathrm{BP} 34 \mathrm{Cr} 10$ in comparison with $\operatorname{Por}\left(5,10,15,20^{-}\right.$ tetraphenylporphyrin) with the concentration of $1 \times 10^{-5}$ $\mathrm{M}$ in dichloromethane. Absorption spectrum of Triad $\mathbf{1}$ is similar to the sum of those of Por, anthracene and viologen and is red-shifted on the addition of BP34Cr10. Fluorescence spectrum of Triad $\mathbf{1}$ is similar to that of Por and is red-shifted with the addition of BP34Cr10. (a)

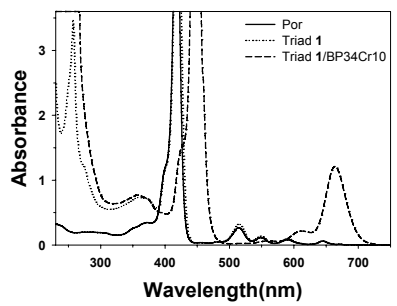

(b)

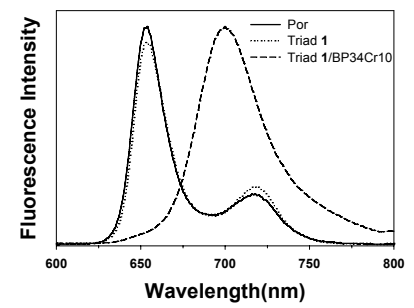

Figure 1. (a) Absorption and (b) fluorescence spectra of Triad 1 (dotted line) and Triad 1/BP34Cr10(1/1) (dashed line) in comparison with Por(solid line).

Figure 2 shows absorption and fluorescence spectra (excitation wavelength $420 \mathrm{~nm}$ ) of Triad 2 and an equimolar mixture of Triad 2 and $\mathrm{BP} 34 \mathrm{Cr} 10$ in comparison with ZnPor(zinc 5,10,15,20tetraphenylporphyrin) with the concentration of $1 \times 10^{-5}$ $\mathrm{M}$ in dichloromethane. Absorption spectrum of Triad $\mathbf{1}$ is also similar to the sum of those of ZnPor, anthracene, and viologen and new red-shifted absorption bands are arisen on the addition of BP34Cr10. Fluorescence spectrum of Triad 2 is similar to that of Por and new red-shifted band is observed on the addition of BP34Cr10. 
(a)

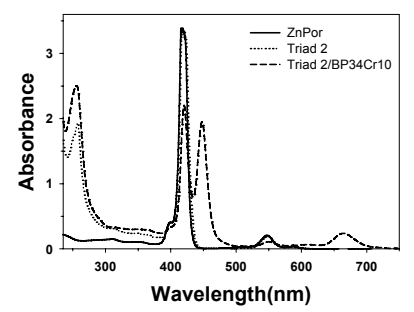

(b)

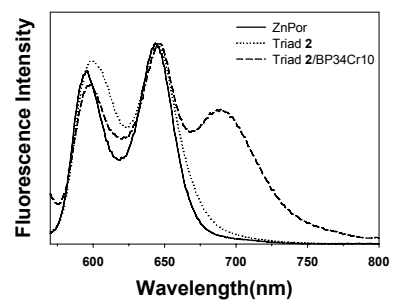

Figure 2. (a) Absorption and (b) fluorescence spectra of Triad 2 (dotted line) and Triad 2/BP34Cr10(1/1) (dashed line) in comparison with ZnPor(solid line).

Further detailed study for the threading and dethreading of Triad 1(or Triad 2)/BP34Cr10 pseudorotaxanes is under investigation.

KEYWORDS : porphyrin, viologen, anthracene, pseudorotaxane

Received June 19, 2013; Accepted July 18, 2013

\section{REFERENCES AND NOTES}

1. Heath, J. R. Annu. Rev. Mater. Res. 2009, 39, 1-23.

2. Klajn, R.; Stoddart, J. F.; Grzybowski, B. A. Chem. Soc. Rev. 2010, 39, 2203-2237.

3. Special issue on Molecular Machines Acc. Chem. Res. 2001, 34, 409-522.

4. Balzani, V.; Credi, A.; Raymo, F. M.; Stoddart, J. F. Angew. Chem. Int. Ed. 2000, 39, 3348-3391.

5. Balzani, V.; Go'mex-Lo'pez, M.; Stoddart, J. F. Acc. Chem. Res. 1998, 31, 405-414.

6. Sauvage, J.-P. Acc. Chem. Res. 1998, 31, 611-619.

7. Nepogodiev, S.; Stoddart, J. F. Chem. Rev. 1998, 98, 1959-1976.

8. Dietrich-Buchecker, C. O.; Sauvage, J.-P. Chem. Rev. 1987, 87, 795-810.

9. Leigh, D. A.; Wong, J. K. Y.; Dehez, F.; Zerbetto, F. Nature 2003, 424, 174-179.

10. Tachibana, Y.; Kihara, N.; Furusho, Y.; Takata, T. Org. Lett. 2004, 6, 4507-4509.

11. Nguyen, T. D.; Liu, Y.; Saha, S.; Leung, K. C.F.; Stoddart, J. F.; Zink, J. I. J. Am. Chem. Soc. 2007, 129, 626-634.

12. Guidry, E. N.; Cantrill, S. J.; Stoddart, J. F.; Grubbs, R. H. Org. Lett. 2005, 7, 2129-2132.

13. Ashton, P. R.; Ballardini, R.; Balzani, V.; Credi, A.; Dress, K. R.; Ishow, E.; Kleverlaan, C. J.; Kocian, O.; Preece, J. A.; Spencer, N.; Stoddart, J. F.; Venturi, M.; Wenger S. Chem. Eur. J. 2000, 6, 3558-3574.

14. Balzani, V.; Credi, A.; Venturi, M. Pure Appl. Chem. 2003, 75, 541-547.

15. The Porphyrin Handbook; Kadish, K. M., Smith, K. M., Guilard, R., Eds.; Academic Press: San Diego, U. S. A., 2000; Vols. 1-10.

16. Wasielewski, M. R. Chem. Rev. 1992, 92, 435-461 and J. Org. Chem. 2006, 71, 5051-5066.

17. Gust, D.; Moore, T. A.; Moore, A. L. Acc. Chem. Res. 1993, 26, 198-205; 2001, 34, 40-48; 2009, 42, 1890-1898.

18. Moon, K.; Kaifer, A. E. Org. Lett. 2004, 6, 185188.

19. Shin, E. J. Bull. Korean Chem. Soc. 2006, 27, 1897-1899.

20. Lindsey, J. S.; Prathapan, S.; Johnson, T. E.; Wagner, R. W. Tetrahedron 1994, 50, 8941-8968.

21. Park, J. E.; Shin, E. J. Spectrochim. Acta A: Mol. Biomol. Spectrosc. 2007, 68, 554-560.

22. Anelli, P. L.; Ashton, P. R.; Ballardini, R.; Balzani, V.; Delgado, M.; Gandolfi, M. T.; Goodnow, T. T.; Kaifer, A. E.; Philp, D.; Pietraszkiewicz, M.; Prodi, L.; Reddington, M. V.; Slawin, A. M. Z.; Spencer, N.; Stoddart, J. F.; Vicent, C.; Williams, D. J. J. Am. Chem. Soc. 1992, 114, 193-218.

23. Raymo, F. M.; Houk, K. N.; Stoddart, J. F. J. Am. Chem. Soc. 1998, 120, 9318-9322.

24. Capobianchi, S.; Doddi, G.; Ercolani, G.; Mencarelli, P. J. Org. Chem. 1998, 63, 80888089.

25. ${ }^{1} \mathrm{H}-\mathrm{NMR}\left(400 \mathrm{MHz}, \mathrm{CD}_{3} \mathrm{COCD}_{3}, \mathrm{ppm}\right) \delta 9.33(4 \mathrm{H}$, $\mathrm{m}$, viologen), $8.89(6 \mathrm{H}, \mathrm{t}, J=8.05 \mathrm{~Hz}$, pyrrole), $8.84(4 \mathrm{H}, \mathrm{m}$, viologen $), 8.79(2 \mathrm{H}, \mathrm{d}, J=4.68 \mathrm{~Hz}$, pyrrole), $8.42(2 \mathrm{H}, \quad \mathrm{d}, \quad J=8.24 \mathrm{~Hz}$, phenyl), $8.32(2 \mathrm{H}, \mathrm{d}, J=8.21 \mathrm{~Hz}$, phenyl), $8.25(2 \mathrm{H}, \mathrm{s}$, anthracene), $7.90-7.70 \quad(16 \mathrm{H}, \quad \mathrm{m}, \quad$ phenyl, anthracene $), 6.16(2 \mathrm{H}, \mathrm{s}$, methylene $), \quad 5.74(2 \mathrm{H}, \mathrm{s}$, methylene), $-2.88(2 \mathrm{H}, \mathrm{s}$, pyrrole-NH). 